\title{
BREITER FÄCHER
}

\section{Liebe Leserin, lieber Leser,}

wie sehen die Fahrzeuge der kommenden 10 bis 20 Jahre aus? Welche Antriebe und welche Features werden in welchen Modellen den Markt dominieren? Die Frage klingt kompliziert, und sie ist es auch. Klar ist, dass die aktuellen und zukünftigen Emissionsgesetzgebungen zu einer erheblichen Elektrifizierung der Antriebe führen werden. Da sich die Automobilindustrie hierbei nicht auf das Batterieauto verlassen kann, werden in den nächsten 10 bis 15 Jahren die Hybridantriebe unter Nutzung modularer Verbrennungsmotoren eine herausragende Bedeutung einnehmen.

Klar ist auch, dass das Auto nach wie vor stark von Emotionen beeinflusst sein wird. Die emotionale Komponente wird sich nur verschieben. Auch wenn die Elektrifizierung keine Einbußen bei der Sportlichkeit bewirkt, ist es doch klar, dass die „Generation i-phone“ nicht mehr unbedingt Wert legt auf Hubraum und Kilowatt. IT-Features aus der Kategorie Car-toInternet und cloudvernetzte Kommunikation werden in wenigen Jahren wohl mitentscheidend für die Wahl von Modell und Marke sein. Hinzu kommt eine Vielfalt an Fahrerassistenzsystemen, die sowohl hinsichtlich Unterstützung von Längs- und Querdynamik als auch durch viele andere kleine Helferlein als Differenzierungsmerkmal herhalten könnte.

Die Fächerstrategien der Autohersteller zeigen, dass sie sich sowohl bei den technischen Eigenschaften von Verbrennungsmotoren als auch bei der Hybridisierung und bei den IT-Merkmalen so aufstellen, dass sie möglichst viele Nischen besetzen. Das mag auf den ersten Blick aussehen, als wüssten Hersteller, Zulieferer und Dienstleister nicht, wohin die Reise geht. Letztendlich ist aber die Entwicklung bei den Techniken zur $\mathrm{CO}_{2}$-Reduktion - vom Gesetzgeber bedingt - von einer hohen Dynamik geprägt. Gleiches gilt für den IT-Bereich. Das macht es speziell für Full-Size-Hersteller notwendig, auf verschiedenen Bühnen gleichzeitig zu spielen. Die Politik täte gut daran, nun etwas Ruhe einkehren zu lassen, um den Herstellern und nicht zuletzt auch den Kunden die Möglichkeit der Orientierung zu geben.

Die Entwicklungen im Automotive-Sektor sind so spannend und dynamisch wie schon lange nicht mehr. Am spannendsten ist aber die Frage, was der Kunde von morgen wohl goutieren wird. Hier gilt es, heute schon vorne mit dabei zu sein, um einen „Me too“-Effekt zu vermeiden und dem Kunden von morgen heute schon den Wert der Marke zu vermitteln.

Herzlichst, Ihr

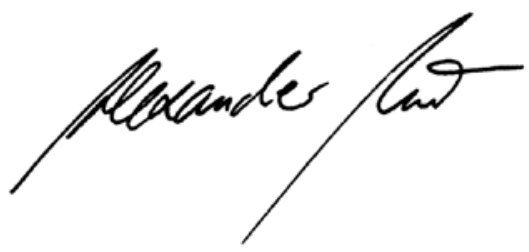

DR. ALEXANDER HEINTZEL, Chefredakteur Wiesbaden, 28. Januar 2013

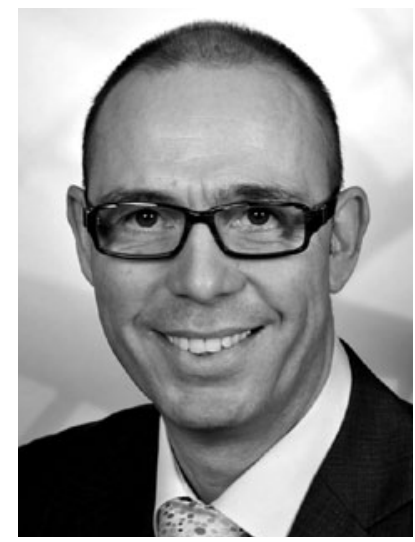

DYNA4 Advanced Powertrain

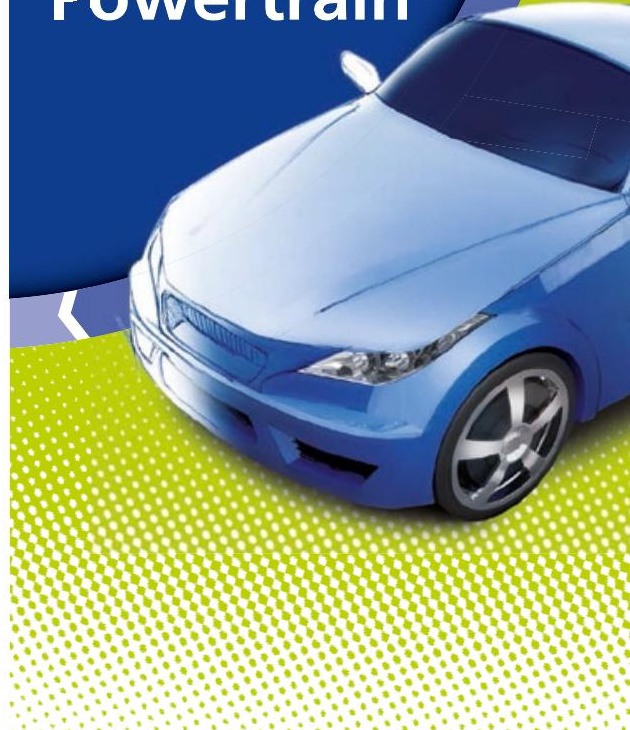

Energiemanagement im Fahrzeug

- Simulation von Einzelfahrzeugen bis hin zur Fahrzeugflotte

- Fahrleistungs- und Verbrauchsberechnungen

- Konventionelle Antriebe, Hybridund Elektrofahrzeuge

- Variantenhandling, Automation und Reporting

Mehr erfahren unter www.tesis-dynaware.com/flv 